\title{
Mashups for Learning - Guest Editorial
}

\author{
doi:10.3991/ijet.v5s1.1190 \\ Martin Ebner ${ }^{1}$, Ralf Klamma ${ }^{2}$ and Sandra Schaffert ${ }^{3}$ \\ ${ }^{1}$ Graz University of Technology, Graz, Austria \\ ${ }^{2}$ RWTH Aachen University, Germany \\ ${ }^{3}$ Salzburg Research, Salzburg, Austria
}

\begin{abstract}
The special track "Mashups for Learning" (MASHL 2009) took place within the "International Conference on Interactive Computer Aided Learning” (ICL 2009) in Villach, Austria. Personal Learning Environments (PLE) are the application type for mashing up learning services. We asked for contributions for an increasing research field. MASHL 2009 provided an excellent space for discussions in order to improve the learning and teaching routines of tomorrow. This special issue consists of the outcomes of this intensive process with international experts.
\end{abstract}

Index Terms-Editorial, Learning Environment, Mashup, Technology Enhanced Learning

\section{INTRODUCTION}

Even outside of learning management systems (LMS) learners have an impressive and constantly rising amount of learning content and tools: Wikis, Weblogs, media portals as FlickR or YouTube or social networking sites as MySpace or LinkedIn offer a lot of (learning) opportunities that are not always easy to handle and organise. Nowadays it is just common to use the World Wide Web as information resource for learning tasks or communicate through different applications. Web 2.0 used prominently by Tim O’Reilly [1], changed the users' role to a much more active one and gave them the possibility to take part on the Internet. Downes [2] named the use of Web 2.0 applications for learning purposes deductive as elearning 2.0 and described for the first time a considerable step towards a more flexible learning and teaching behaviour. In consequence research in technology enhanced learning concentrated on a meaningful use of applications such as Wikis, Weblogs, Podcasts and also different kind of social media.

Because of the dramatically increasing data on the Web as well as the big amount of open resources teaching and learning is basing more and more on distributed content. Therefore the need for bringing together these different kinds of stuff become obvious and leads to the concept of mashups.

Web-based mashups are a technology that merges data and/or functionalities from different Web sources. In detail mashups are considered to be both a concept and technology for merging content, services and applications from multiple web sites in an integrated, coherent way [3], [4]. This means that less special knowledge is needed to create a mashup. Mainly basic programming expertise for integrating different APIs and other data sources are required [5]. It can pointed out that merging content can give a great potential for learning behaviours of tomorrow [6].
An example for mashups for learners is the concept of Personal Learning Environments (PLE) and their current implementations. Besides, various prototypes and tools also try to support community of practice and learners by combining resources in an effective way. Additionally, smart applications are developed to add-on filtering and recommender systems, reputation systems, engagement indicators, personalisation opportunities or quality assurance concepts to support learning within the Web 2.0.

Building on this ideas, we organised a special track called "Mashups for Learning" (MASHL 2009), which took place within the "International Conference on Interactive Computer Aided Learning” (ICL 2009) in Villach, Austria. In this special track we wanted to bring together new and innovative approaches, applications and experiences with mashups for learners, building on and combining common Web 2.0 applications:

- Personal learning environments as well as support of communities of learners;

- new concepts and implementations of mashups for learning;

- technical implementations and working examples for mashups;

- studies on work and evaluation of mashups for learning;

- conceptual design and studies on work of special aspects as recommendations or reputation systems within mashups;

- current and future developments concerning technology and pedagogy.

We asked for contributions to take care about an increasing research topic in the field of technologyenhanced learning and to provide the possibility for discussion to improve the learning and teaching behaviour of tomorrow. Besides the contribution within this issue we had also presentations of three short papers at the conference dealing with the topic of the call.

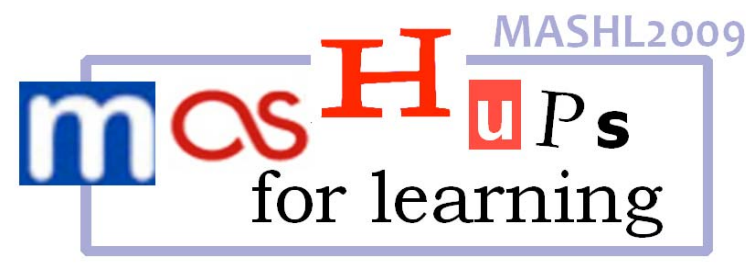

Figure 1. Logo of the Special Track "Mashups for Learning” 


\section{THIS IsSUE}

The five papers selected to be part of this special issue about mashups for learning are following briefly described.

\section{A. Recommender System for Mashups}

ReMashed is a research prototype of a community system with recommender functionalities that aggregates several Web resources as RSS-feeds, Bookmarks and tags. The article describes the usability study on ReMashed. Users were invited to specify their daily used Web 2.0 services and were asked to rate information they get from the implemented recommender system, which should fit to their personal needs. Beside the description of the running system an evaluation points out its usefulness. Hendrik Drachsler and his co-authors got the best paper award for this contribution.

\section{B. Avantgarde Pedagogical Practise Utilizing Virtual Environments}

Virtual Worlds, in this case Second Life, are used to enhance motivation and engagement of learners. By bringing together new and interesting tools it was possible to gather student motivation. The students were asked to make videos as a reflection of their learning processes and results within the course. The usage of the screen capturing technique Machinima made it easy and joyful to shot a film in a virtual world. The paper by Naomi Dreher and Heinz Dreher described the whole virtual environment as well as the screen capturing technique Machinimia used running this course.

\section{Awareness and Transperency in Social Software}

Wolfgang Reinhardt and Sascha Rinne contribute with an innovative approach of a community-embedded collaborative development environment (CCDE). The presented prototype gives a first overview of the used technique, the requirements and will prepared for a first evaluation among students. The combination of a collaborative development environment with the advantage of communities of interest carries out that also a mashup in the background (connecting data from various sources) have to taken into account for learning purposes.

\section{Conceptual Study of a PLE}

A first prototype for a university wide PLE at the Graz University of Technology is described in the contribution of Behnam Taraghi and his colleagues. The technological concept of a widget-based framework as well as design studies show how such an environment can support students in Higher Education effectively. Finally, the prototype is shown to get a first impression how such a flexible environment can look like.

\section{E. Collaborative Develompent of a PLE for language learning}

The final part gives an insight into an experimental and distributed widget-based PLE with a special focus on language learning needs. The planning and development phase as well as the resultant requirements are described and show the interdisciplinary of learning environments. In the end different widgets used in the project are pointed out and critically discussed by Dominik Renzel and his coauthors.

\section{PROGRAM COMMITTEE}

We like to thank our program committee, which reviewed the submitted contributions for the special track in a double-blind review process:

- Graham Attwell, Pontydysku, UK

- Andreas Auinger, University of Applied Science Steyr, AT

- Tobias Bürger, Semantic Technology Institute Innsbruck, AT

- Cristina Costa, University of Salford, UK

- Hendrik Drachsler, OUNL, NL

- Jon Dron, University of Athabasca University, CA

- Sebastian Fiedler, Centre for Social Innovation, AT

- Christian Glahn, OUNL, NL

- Gabriela Grosseck, West University of Timisoara, ROU

- Wolf Hilzensauer, Salzburg Research, AT

- Andreas Holzinger, Medical University Graz, AT

- Sandra Hofhues, University of Augsburg, DE

- Marco Kalz, OUNL, NL

- Ralf Klamma, RWTH Aachen University, DE

- Narayanan Kulathuramaiyer, University Malaysia Sarawak, MAS

- Teemu Leinonen, University of Helsinki, FI

- Anoush Magaryan, University of Glasgow, UK

- Felix Mödritscher, Vienna University of Economics and BA, AT

- Bill McDaniel, DERI, IRE

- Walther Nagler, TU Graz, AT

- Elaine Pearson, University of Teesside, UK

- Alexander Pohl, University of Munich, DE

- Mandy Schiefner, University of Zurich, CH

- Dirk Schneckenberg, ESC Rennes School of Business, FR

- Rolf Sint, Salzburg Research, AT

- Peter Sloep, OUNL, NL

- Marcus Specht, OUNL, NL

- Scott Wilson, CETIS, UK

- Steve Wheeler, University of Plymouth, UK

- $\quad$ Fridolin Wild, OU, UK

\section{ACKNOWLEDGMENT}

Beside the members of the program committee and their work we like also to thank our partners from the ROLE project (www.role-project.eu/): The ROLE project provides us with a present for the best paper award. Many thanks also to Herbert Mühlburger who assisted us publishing this journal. We are equally indebted to Professor Dr. Michael Auer for his interest and collaboration with MASHL 2009 and that we can became part of his international conference. Last but not least, thanks to the many unnamed special track participants who contributed to the tracks and being part of this successful event. 


\section{REFERENCES}

[1] T. O’Reilly, “What is Web 2.0 Design Patterns \& Business Models for the Next Generation of Software” http://www.oreillynet.com/ pub/a/oreilly/tim/news/2005/09/30/what-is-web-20.html. (last access: January, 2010).

[2] S. Downes, “e-Learning 2.0,” in ACM e-Learn Magazine, vol. 10, October 2005.

[3] R. Tuchinda, P. Szekely, and C. A. Knoblock, "Building Mashups by example," in Proceedings of the 13th International Conference on Intelligent User Interfaces 2008, pp. 139-148, 2008.

[4] E. Ort, S. Brydon, and M. Basler, "Mashups Styles, Part 1: Server-Side Mashups” (Sun Microsystems). http://java.sun.com/ developer/technicalArticles/J2EE/mashup_1/ (last access: January, 2010)

[5] N. Zang, M. B. Rosson, and V. Nasser, "Mashups: who? what? why?,“ in $\mathrm{CHI}$ '08 extended abstracts on Human factors in computing systems 2008, pp. 3171-3176, 2008.

[6] A. Auinger, M. Ebner, D. Nedbal, and A. Holzinger, "Mixing Content and Endless Collaboration - MashUps: Towards Future
Personal Learning Environments,” in Universal Access in HumanComputer Interaction. Applications and Services, Springer Lecture Notes in Computer Science, vol. 5616/2009, pp. 14-23, 2009.

\section{AUTHORS}

M. Ebner is Head of Social Learning Department at Computer and Information Services, Graz University of Technology, Graz (e-mail: martin.ebner@tugraz.at)

R. Klamma leads the research group "metadata in community information systems" at the information systems chair, RWTH Aachen University (e-mail: klamma@dbis.rwth-aachen.de)

S. Schaffert works at Salzburg Research Forschungsgesellschaft mbH in Salzburg, Austria (e-mail: sandra.schaffert@salzburgresearch.at) 